\title{
IMPROVING THE OUTPUT EFFICIENCY OF PV SYSTEMS UNDER FAULT USING FUZZY-CONTROLLED DSTATCOM SYSTEMS
}

\author{
Arjun Singh Solanki \\ M.tech Scholar \\ Department of Electrical and Electronics \\ Oriental University, Indore, M.P., India
}

\begin{abstract}
DStatcom based frameworks have demonstrated themselves to be successful as far as force quality improvement for dispersed frameworks. The force necessities of the present continuous burdens are commonly not fulfilled by a solitary force source, along these lines there is a need to add different buyer benevolent sources to the framework. These sources may add commotion and issues to the force framework, consequently there is a need to settle this force utilizing power frameworks. In this proposal, we have chipped away at improving the general force nature of a circulated age framework which consolidates electrical lattice-based age and photograph voltaic-based (PV) age. In any case, the voltage variety in PV age can result harm in client apparatuses and other force quality issues as side-effects. STATCOM based models have proven to be good in terms of improving overall efficiency of PV-based systems. In this paper, we propose a DSTATCOM based Fuzzy model to control the power of PV-based systems for maximal power output under different fault conditions.
\end{abstract}

Keywords: PV, STATCOM, Fuzzy

\section{INTRODUCTION}

By and by, the usage of reasonable force source is progressively positive in both financially and normally. The enthusiasm for supportable force source has extended essentially during the time in sight of inadequacy of oilbased goods and nursery sway. Among contrasting sorts of manageable force sources, daylight-based essentialness and wind imperativeness have gotten extraordinarily standard and mentioning because of current advancement world. Today, PV sources are used in various central focuses, for example, freed from sullying. Sun based electric imperativeness demand has grown reliably by $20 \%-25 \%$ once per year over from the preeminent ongoing 20 years with decreasing costs and expenses. sun

\author{
Dr. Dolly Thankachan \\ Associate Professor and Head \\ Department of Electrical and Electronics \\ Oriental University, Indore, M.P., India
}

oriented cell inverter is utilized to differ over dc power into air con power obtained from PV modules to be dealt with into the pile. Therefore, improvement in yield waveform and execution of the inverter lessens its different consonant substance made by trading action of the inverter. As recently, amazed inverters have gotten logically appealing for authorities and makers because of their focal points over standard three-level heartbeat width-managed (PWM) inverters. These sorts of inverters offer improved yield waveform, humbler change size, lower electromagnetic impedance EMI, bring down full THD.

For stunned inverter, two or three topologies are described in two social events depending upon the quantity of self-governing dc source. the premier noteworthy working topologies are diode cut (NPC), flying capacitor (FC) and course $\mathrm{H}$-interface (CHB). The FC topology is much the same as the NPC with differentiate that the cut-out diodes are superseded by flying capacitors and CHBs inverters are appointed plan relationship of at least two single-stage $\mathrm{H}$-associate inverters. Basic trading repeat and high trading repeat PWM procedures are used to calculate the fell amazed inverters. it's lower trading mishap and better adequacy. inside the CHB MLI, each level requires an extraordinary dc source and for every dc source a PV cell or battery is to be related. the entirety of the three converter topologies have the potential for application in medium and high voltage applications. All devices are relied upon to have same voltage assessments anyway not so much same current examinations. Stunned inverters consolidate a spread of force semiconductors and capacitor voltage sources, the yield of which produce voltages with wandered waveforms. By growing the quantity of levels inside the inverter, the yield voltages have more advances making a stairway waveform, which includes a diminished ensembles mutilation. Be that since it might, a high number of levels extends the control multifaceted nature and presents voltage lop-sidedness issues. As appear differently in relation to other two, CHB MLI requires insignificant number of sections and has the 
potential for utility interface applications by virtue of its capacities for applying change and sensitive trading methodology. The fell H-Bridge inverter doesn't use half expansion in each level recognize full $\mathrm{H}$-interface inverter in sight of more adequacy in yield. the ensuing portion delineates the changed techniques used for controlling the PV systems, trailed by the proposed model in conclusion the results and discernments that we've gotten from the structure.

\section{LITERATURE REVIEW}

Work in [1] have proposed an assessment, which not simply allows a decent extent of information voltage, yet also reimburses unbalance current of the close by trouble in three-phase three-wire PV structure with the assistance Dual-Level Four Leg Inverter

Work in [2] focuses round the structure, showing and control of force converters for power quality improvement during a lattice related Distributed Generator system. during this paper Photovoltaic is considered as DG. All the propagations are cleared out MATLAB/Simulink condition and. the results with vainglorious assessment are appeared.

Work in [3] have introduced a contraption to be explicit one of a kind voltage restorer (DVR) considering photovoltaic (PV) age/battery units to upgrade voltage quality during a microgrid. The restorer is identified with the system by a rectifier, which is in course of action with the point of typical coupling (PCC). Using essentialness, the board system (EMS), the proposed contraption may be worked under one of a kind voltage restorer mode, constant power nimbly mode and scaled down scale source mode, and be traded effectively among them. The dynamic voltage restorer could influence voltage hang or flood, and during thusly improves the power quality in microgrid

Work in [4] have taken an endeavor at Photovoltaic (PV) structures which are cross section related by methods for an interfacing converter which works with Maximum point Tracking (MPPT) controller so on post of the lattice by the chief outrageous sensible daylight based power. during this paper, the PV interfacing inverter is controlled using an insightful control strategy to play out the 2 components of force quality improvement despite moving the PV most extraordinary ability to the system. A Fuzzy reason control computation is applied for MPPT.

Work in [5] have used segregated channels which fuse LC, LCL and LLCC channel topologies. A relationship examination of the whole symphonious mutilation decline with the above channels is done. Further, the paper attempts to call attention to that the utilization of LLCC channel with an autonomous PV structure can particularly improve the power idea of the system. Results are checked using proliferations in MATLAB-SIMULINK condition.

Work in [6] have proposed transport static compensator for advancement of force quality using PV cell. Dstatcom is utilized for diminishing the responsive power that occurred due to varying kinds of weight on the spread systems. The Dstatcom is utilized for reimbursing sounds at PCC.

Work in [7] have shown the execution of a passed on age converter is updated to decrease the power mishap and improving the impact quality. a particular structure of force electronic based converter made by two voltage source inverters is proposed. These two inverters are equivalent related together and expected to offer system relationship of a one-phase scattering age resource.

Work in [8] have proposed a scattering static composed compensator (D-STATCOM) for power quality improvement in nonconcurrent machine-based flowed age in light of the fact that the strange generator has poor voltage rule interestingly, during top weight conditions. Use of D-STATCOM as voltage controller improves the general execution of the spread system basically. the following stage might be a dc/dc change stage, which gives the confinement and, in this manner, the immovably controlled yield voltage to fulfill the dc transport requirements. With a by and large oversaw input voltage and an immovably controlled yield of transport voltage level, this converter can when in doubt achieve near the precarious edge of $92 \%$ capability under hard trading exercises and $94 \%$ adequacy under fragile trading undertakings even with trading frequencies more than $100 \mathrm{kHz}$. The circuit topology are regularly single completed for power levels inside the extent of two or 300 watts, yet over a kilowatt, a full expansion topology is commonly required [9-12].

\section{PROPOSED SYSTEM}

The block diagram of the proposed model can be shown from the following figure,

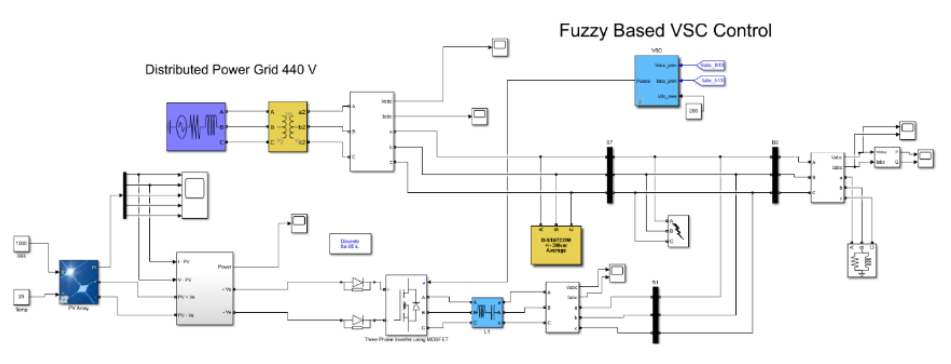

Figure. Proposed model

The model has the following working principle, 
- The current and voltages from the distributed grid are fed into the load

- DSTATCOM is connected on the source side, and power is fed to the load via the DSTATCOM

- The fault generator block introduces faults into the system

- The faults are compensated using the DSTATCOM controller

- A PV array is connected to add-in more power to the input of the system

- DSTATCOM output is given to the PV array for further control

- Power from Grid and PV array is combined and given to the load

The following parameters are taken for each of the blocks,

\begin{tabular}{|c|c|c|c|}
\hline \multirow[b]{2}{*}{$\begin{array}{l}\text { Block } \\
\text { Name }\end{array}$} & \multirow[b]{2}{*}{ Parameters } & & Measurements None \\
\hline & & \multirow{4}{*}{$\begin{array}{l}\text { DSTATC } \\
\text { OM } \\
\text { control } \\
\text { parameters }\end{array}$} & D-STATCOM Controller (mask) \\
\hline \multirow{16}{*}{$\begin{array}{l}\text { Three } \\
\text { phase } \\
\text { sources }\end{array}$} & \multirow{3}{*}{$\begin{array}{l}\text { Three-Phase Source (mask) (link) } \\
\text { Three-phase voltage source in series with RL branch. }\end{array}$} & & Parameters \\
\hline & & & \multirow{2}{*}{$\begin{array}{l}\text { Mode of operation: Voltage regulation } \\
\text { AC voltage setpoint Vref }(\mathrm{pu}) \text { : }\end{array}$} \\
\hline & & & \\
\hline & Parameters Load Flow & & 1.0 \\
\hline & Configuration: $\mathrm{Yg}$ & 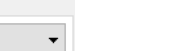 & Manual mode: Qref (Reactive power in pu): \\
\hline & Source & & \\
\hline & $\square$ Specify internal voltages for each phase & & 1000 \\
\hline & Phase-to-phase voltage (Vrms): 440 & $\vdots$ & Vac Regulator Gains: [ Kp Ki ] \\
\hline & Phase angle of nhase A (dearees). 0 & : & {$[0.80250]$} \\
\hline & Phase angle of phase $\mathrm{A}$ (degrees): 0 & $\vdots$ & Vdc Regulator Gains: [ Kp Ki ] \\
\hline & Frequency $(\mathrm{Hz}): 50$ & $\vdots$ & {$\left[\begin{array}{ll}0.01 & 0.15] \\
\end{array}\right.$} \\
\hline & Impedance & & Current Regulators Gain: [ Kp Ki Kd ] \\
\hline & $\square$ Specify short-circuit level para & eters & $\begin{array}{l}{\left[\begin{array}{ll}{[0.82000]} \\
\text { Sample time (s) }\end{array}\right.} \\
\end{array}$ \\
\hline & 3-phase short-circuit level at base voltage(VA): $100 \mathrm{e} 6$ & : & \\
\hline & Base voltage (Vrms ph-ph): 440 & $:$ & \\
\hline & X/R ratio: 7 & $\begin{array}{l}\text { Internal } \\
\text { DSTATC } \\
\text { OM }\end{array}$ & \multirow{8}{*}{ 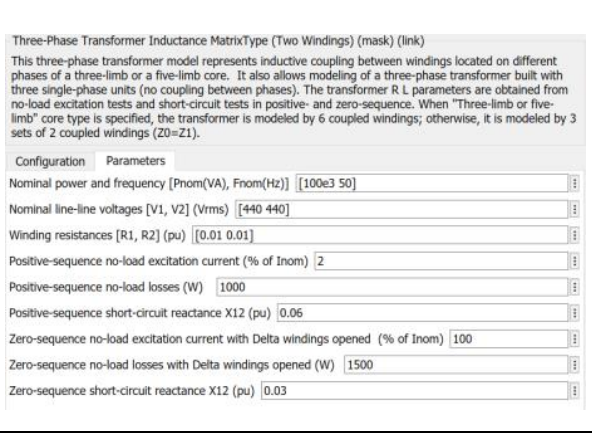 } \\
\hline \multirow{15}{*}{$\begin{array}{l}\text { Three } \\
\text { phase } \\
\text { transforme } \\
\text { rs }\end{array}$} & Three-Phase Transformer Inductance MatrixType (Two Windings) (mask) (link) & transforme & \\
\hline & \multirow{5}{*}{\multicolumn{2}{|c|}{ 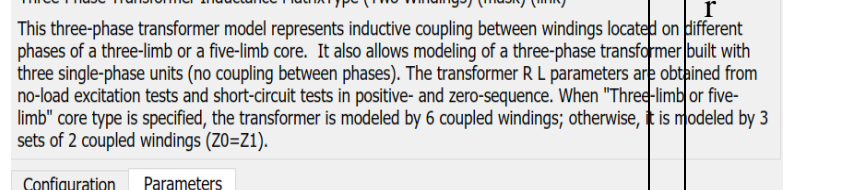 }} & \\
\hline & & & \\
\hline & & & \\
\hline & & & \\
\hline & & & \\
\hline & $\begin{array}{l}\text { Configuration Parameters } \\
\text { Nominal power and frequency [Pnom(VA), Fnom(Hz)] [100e3 50] }\end{array}$ & : & \\
\hline & Nominal line-line vottages [V1, V2] (Vrms) [440 350.03] & & \\
\hline & Winding resistances $[R 1, \mathrm{R} 2](\mathrm{pu})[0.010 .01]$ & PVArray & $=0$ \\
\hline & Positive-sequence no-load excitation current (\% of Inom) 2 & : & sine \\
\hline & Positive-sequence no-load losses (W) 1000 & $\bar{\vdots}$ & 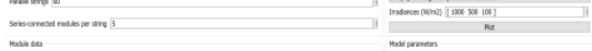 \\
\hline & Positive-sequence short-circuit reactance X12 (pu) 0.06 & $\square:$ & $=-\sin =0$ \\
\hline & Zero-sequence no-load excitation current with Delta windings opened (\% of Inom) 100 & $\square:$ & 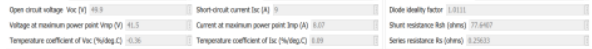 \\
\hline & Zero-sequence no-load losses with Delta windings opened (W) 1500 & & \\
\hline & Zero-sequence short-circuit reactance X12 (pu) 0.03 & $\square \vdots$ & \\
\hline
\end{tabular}

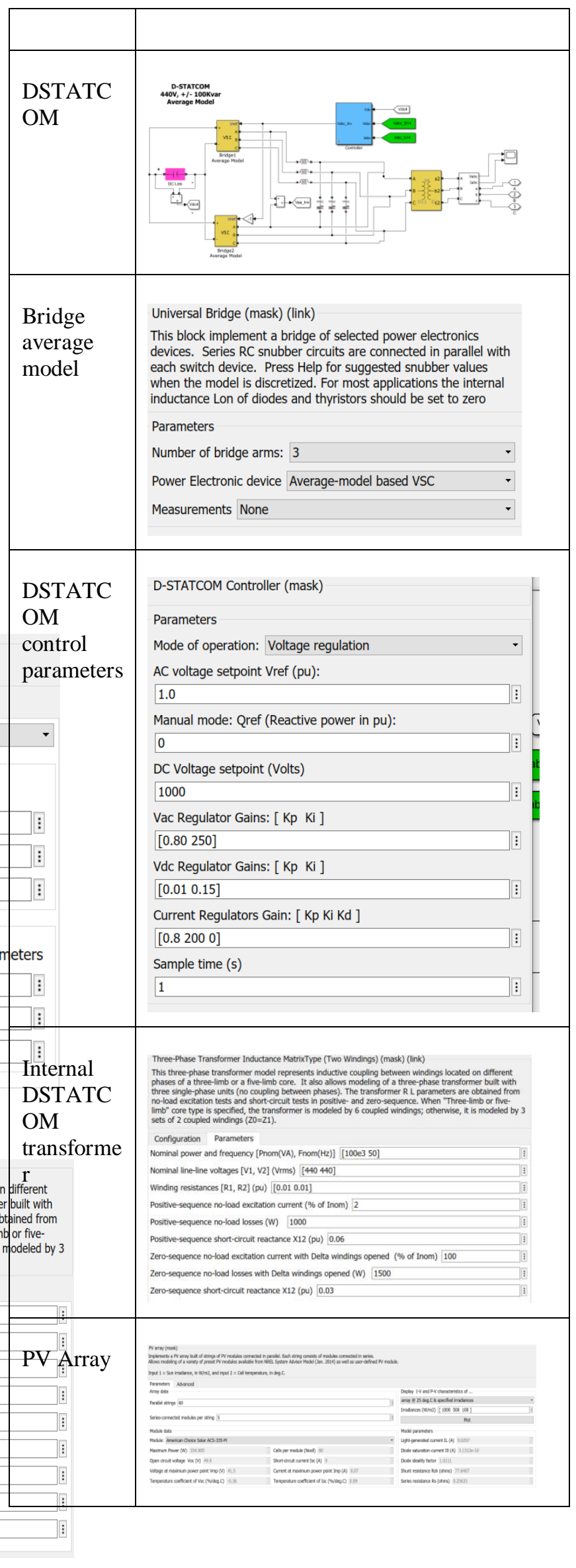




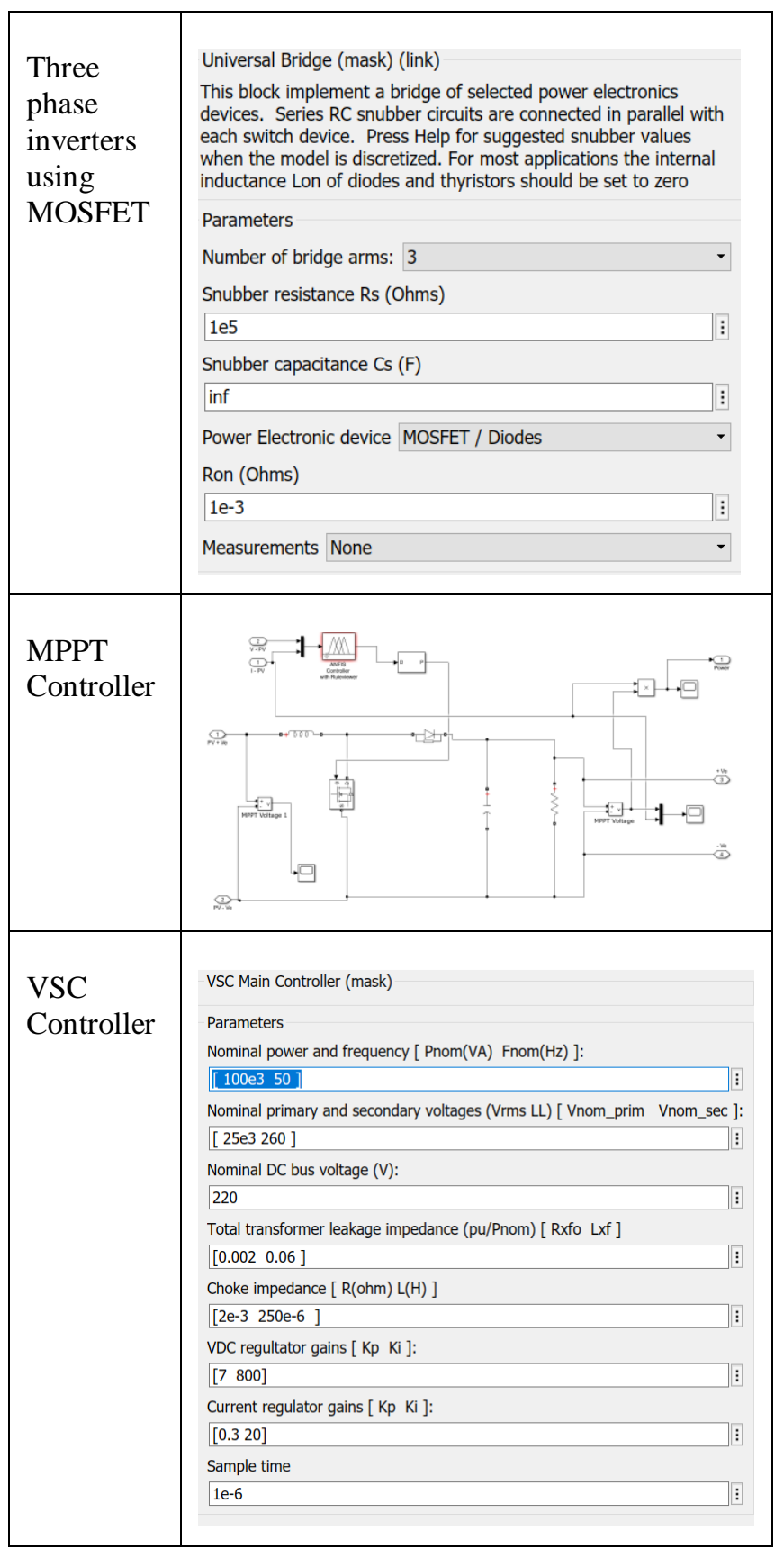

Table. The details about each of the blocks

From the given table we can observe that the blocks are made to be in synchronization with each other using similar frequency, voltage and current values. The flowchart of the system can be seen in the following diagram,

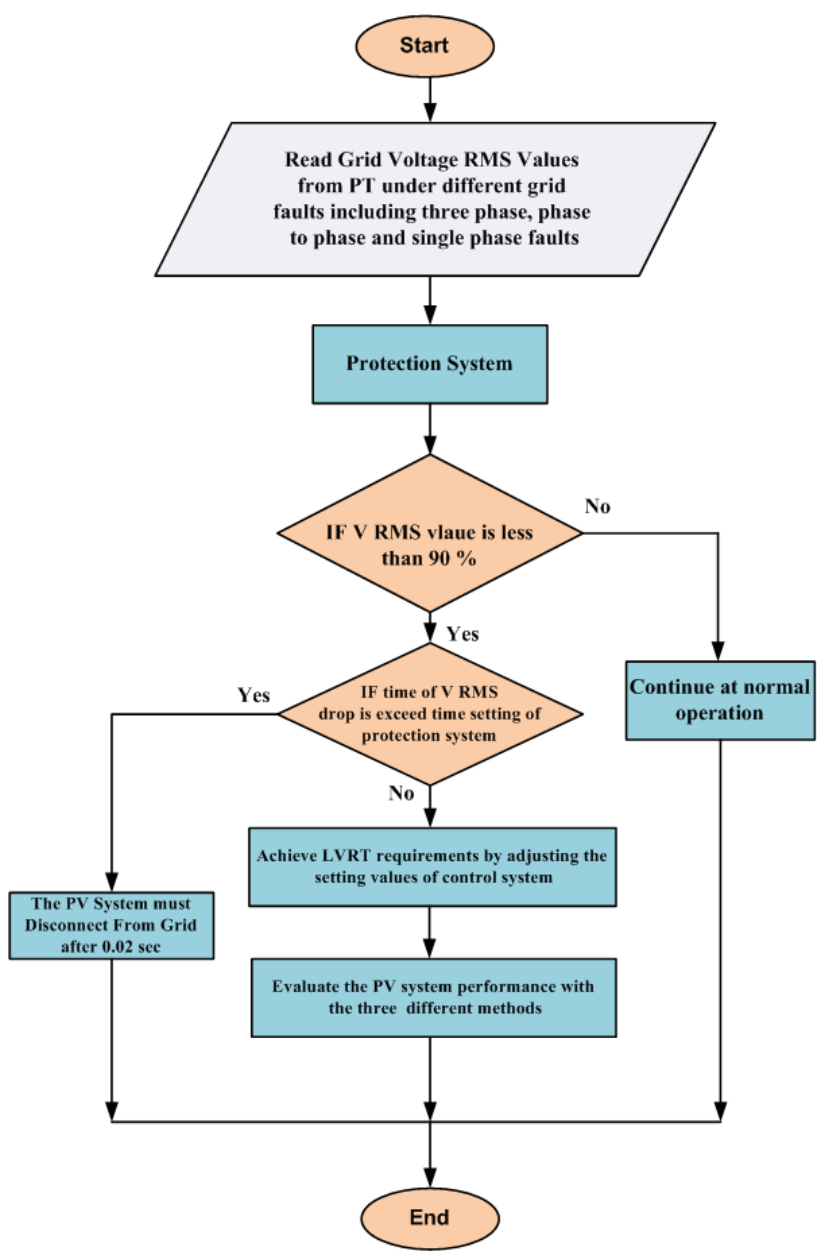

Fig. 1 Flowchart of the system

From the flowchart we can observe that the system is finding out the most optimum parameters, followed by DSTATCOM based Fuzzy control. This control helps in evaluating the best results for the system. The results of the system can be observed from the next section.

\section{RESULT ANALYSIS}

First, we observed the current when DSTATCOM is not connected and fault is introduced. From the figure we can observe a change in the current values as soon as the fault is added to the system,

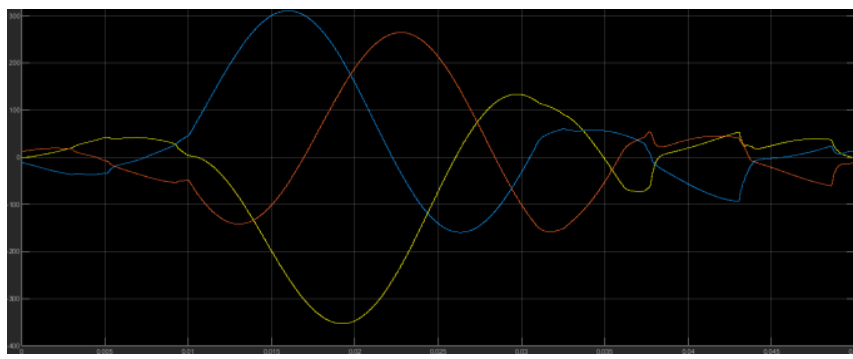

Fig 1 Three phase unbalanced current when DSTATCOM is not connected to transmission lines and fault is introduced 
Similar observations are made for the voltages, and results are showcased in figure 2 as follows,

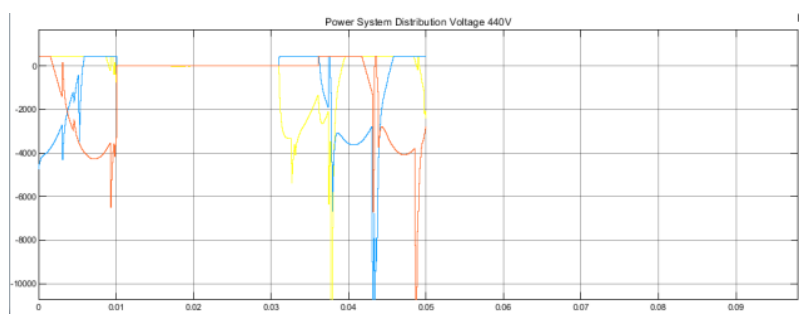

Fig 2. Three phase voltages when DSTATCOM is not connected to transmission lines and fault is introduced

From the figures we can observe that the voltages and currents are varying abruptly and the overall system stability is compromised due to addition of faults. This needs to be addressed, but first let's understand the effect of varying the irradiance on the output of the PV array. These results are given from the figures 3, 4, 5 and 6 as follows. As we can see, the results showcase that an increase in the irradiance level should always increase the power, voltage and current outputs of the PV array. But, this power is limited by the PV model used, and further increasing the irradiance will not vary the power output.

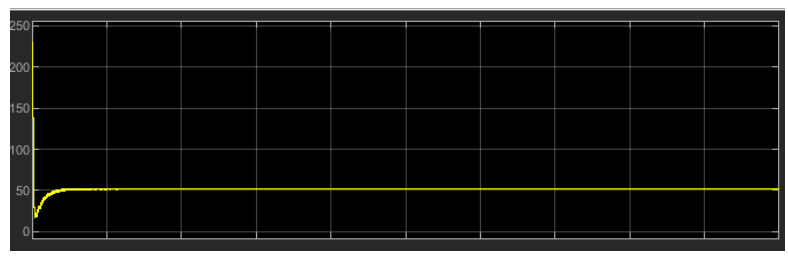

Fig 3 Current graph obtained from PV array when Irradiance $=1000 \mathrm{~W} / \mathrm{m} 2$ and temperature $=25$ degree celcius

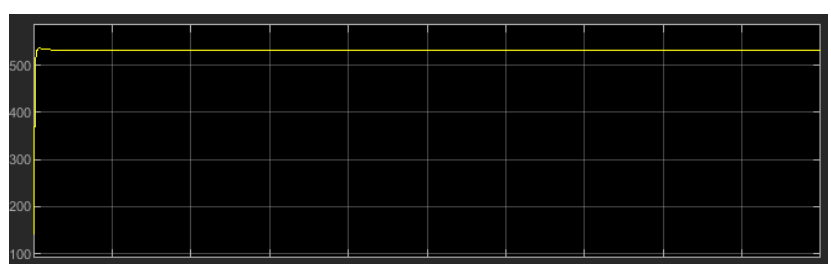

Fig4 Voltage graph obtained from PV array when Irradiance $=1000 \mathrm{~W} / \mathrm{m} 2$ and temperature $=25$ degree Celsius

From the results we can observe that,

- $\quad$ The MPPT is able to obtain the maximum allowed voltage

- Due to ANFIS the stability of the circuit is optimum

- There are no spikes, lags or swings in the output voltage

- Current waveforms are stable due to MPPT
- MPPT is able to obtain all these results with minimum power wastage and maximum circuit utilization

- Similar results are obtained for the power of MPPT output

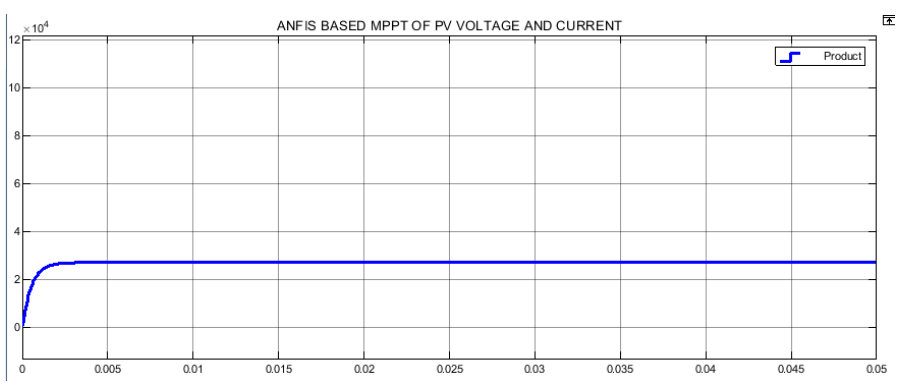

Fig 5 Anfis Based MPPT Power

When DSTATCOM is connected the output follows a proper sinusoidal pattern as expected. This pattern indicates that the circuit is constantly supplying high quality power to the output grid.

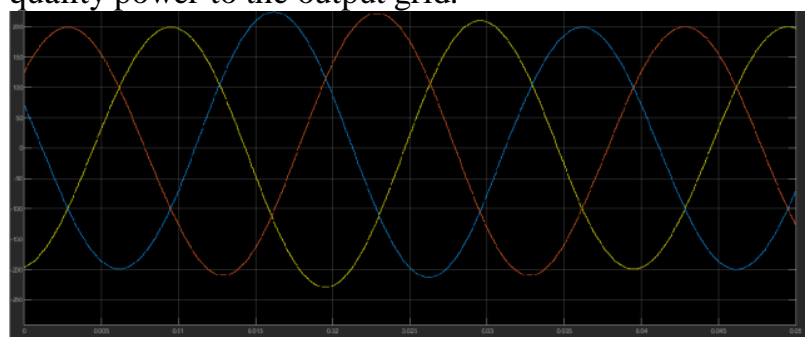

Fig 6 Three phase balanced currents when DSTATCOM is connected to transmission lines

When faults are introduced, the output voltages and currents do change, but the changes as well inside admissible limits, as observed in figure 8 . We then varied the irradiance, and observed the changes in the output voltages. Even though the irradiance is changed, then too the output does not change that much due to the incorporation of DSTATCOM. This can be observed in figure 7 as follows,

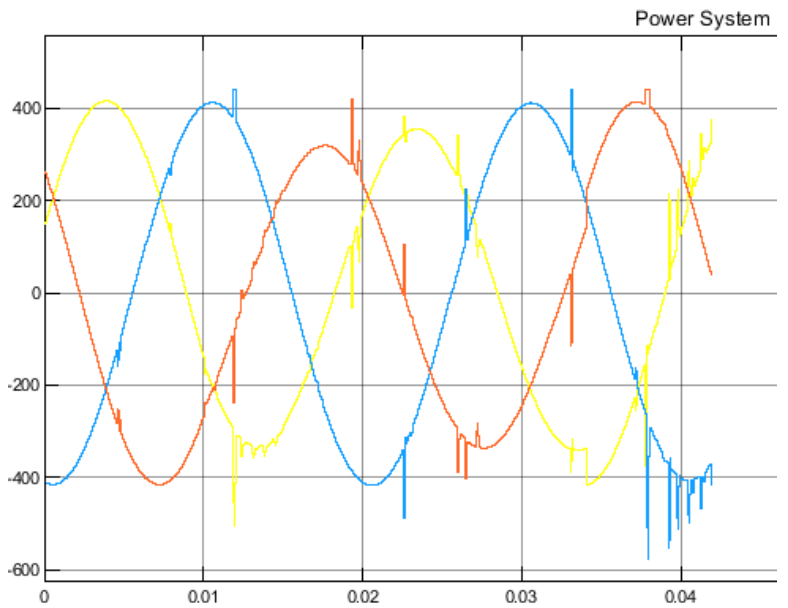


Fig 7. Three phase voltages when DSTATCOM is connected to transmission lines and fault is introduced

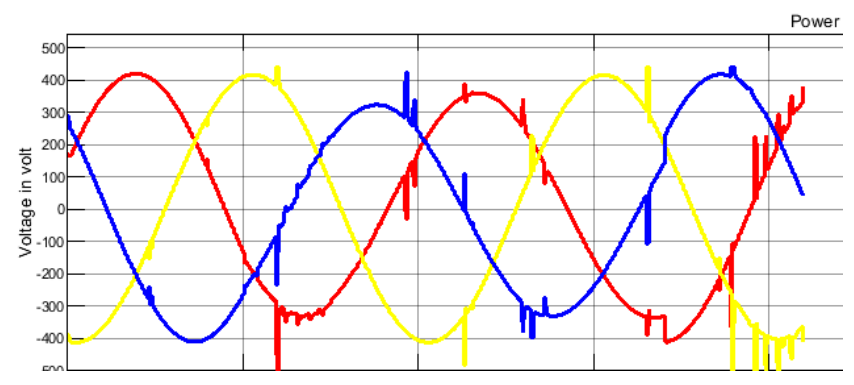

Fig 8 . Three Phase voltage at the output of three phase inverter when irradiance $=800 \mathrm{~W} / \mathrm{m} 2$

Similarly, irradiance variation outputs can be observed from following figure,

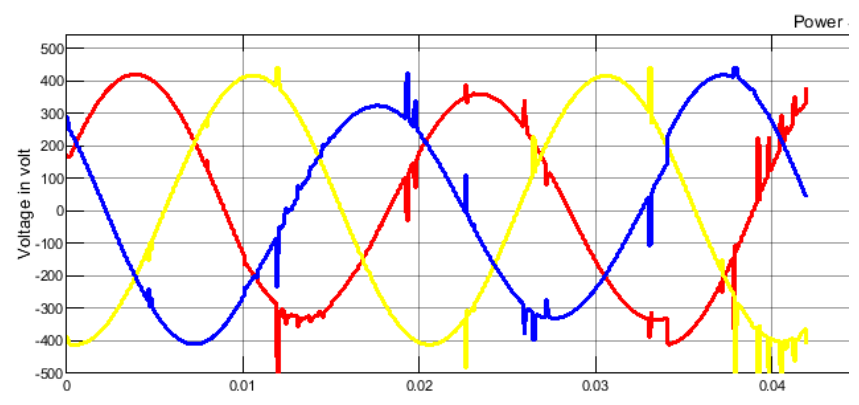

Fig 9. Three Phase voltage at the output of three phase inverter when irradiance $=1000 \mathrm{~W} / \mathrm{m} 2$

From these results we can observe that the disturbances in the power are mitigated due to the usage of DSTATCOM with Fuzzy system, and the system's efficiency is improved.

\section{CONCLUSION}

The proposed system is able to reduce variations in the output which might arise due to variations in input current, voltage or any faults. Fuzzy MPPT is used in order to improve the power tracking of the solar array, while DSTATCOM does the part of stabilizing the output power patterns. The results indicate that the output waveforms vary in the range of less than $5 \%$ of the actual value, thereby improving the overall stability of the system under test. Furthermore, the presence of a wellplanned DSTATCOM with carefully designed parameters is the key to making a better and stable system. In future, researchers can add machine learning and artificial intelligence-based techniques in order to improve the overall quality of the system. Power factors, total hormonic distortion and other analysis can be done in order to further evaluate the system performance.

\section{REFERENCES}

[1] Ghosh A. and Ledwich G., Power Quality Enhancement Using Custom Power Devices, Kluwer Academic Publishers, 2018

[2] IEEE Std. 1159-2015, "IEEE Recommended Practice for Monitoring Electric Power Quality"

[3] Hingorani N.G. and Gyugyi L., Undestanding FACTS, IEEE Press, New York, 2019

[4] Bin Wu, "High-Power Converters and AC Drives",IEEE Press, 2006

[5] Mutluer B., Çadırcı I., Ermis M., et.al., “A Unified Relocatable SVC for Open- Cast Lignite Mining in Turkey”, IEEE Tran. on Ind. Appl., vol.40, no.2,pp. 650663, Mar-April 2004

[6] Mori S., Matsuno K "Development of a Large Static VAR Generator Using Self-Commutated Inverters for Improving Power System Stability", IEEE Tran. on Power Systems, vol. 8, no. 1, pp. 371-376, Feb. 2013

[7] Schauder C., "Development of a $\pm 100 \mathrm{MVAr}$ Static Condenser for Voltage Control of Transmission Systems", IEEE Tran. on Power Delivery, vol.10, no.3, pp.1486-1496, July 2015

[8] Reed G.F., , "Application of a 5MVA, 4.16kV DSTATCOM System for Voltage Flicker Compensation at Seattle Iron\&Metals", IEEE Pow. Eng. Soc. Summer Meet., vol. 3, pp. 1605-1611, July 2000

[9] Grunbaum R., "Enhancing of Power Quality and availability in distribution systems by means of voltage source converters", 16th International Conference and Exhibition on Electricity Distribution, vol.2, (IEE Conf. Publ. No:432) June 2001

[10] Assis T.M.L.de, Watanabe E.H.,.Pilotto L.A.S, "Analysis of Steady State and Dynamic Performance of a Static Synchronous Compensator (STATCOM)", IPST'01, paper no. 219, June 2001

[11] Namuduri C., Sen P.C., "Optimal pulse width modulation for current source inverters", IEEE Tran. Ind. Appl., vol.IA-22, no.6, pp.1052-1072, Nov/Dec. 1986

[12] Malesani L., Tenti , P. "Three-Phase AC/DC PWM Converter with Sinusoidal AC Currents and Minimum Filter Requirements", IEEE Trans. Ind. Appl., vol.IA23, no.1, pp.71-77, Jan/Feb 1987 